\title{
NOBLEZA, PODER Y CONFLICTOS: LA VILLA DE HORTA (FAIAL) EN LOS SIGLOS XVII-XVIII
}

\author{
José DAMIÃo RoDRIGUES \\ Universidade de Lisboa, Faculdade de Letras
}

\begin{abstract}
RESUMEN. El presente texto pretende presentar una caracterización sociológica de la nobleza municipal (a gente nobre da governança) de la villa de Horta (isla de Faial, Azores) en los siglos XVII y XVIII. Además de resaltar las asimetrías existentes en el interior del grupo y las relaciones familiares y de poder, se presentan las causas de conflicto y las conexiones con los representantes de la corona, el corregidor y el juiz de fora. Para finalizar, destacamos los límites de las reformas introducidas en 1766, que pretendían controlar las periferias y el poder de los ayuntamientos. Palabras clave: nobleza; élites locales; poder municipal; conflictos; Horta (Faial, Azores).
\end{abstract}

AbSTRACT. This text aims to present the sociological features of the municipal nobility (the gente nobre da governança) from the town of Horta (island of Faial, Azores) in the $17^{\text {th }}$ and $18^{\text {th }}$ centuries. Besides highlighting ths differences inside the group and the kinship and power relationships, we present the causes of conflict and the relationship with the crown officers, the corregedor and the juiz de fora. Finally, we stress the limits of the reforms that were introduced in 1766, aiming at the control of the peripheries and the power of the municipalities.

Keywords: Nobility; local elites; municipal power; conflicts; Horta (Faial, Azores).

Recibido: 17-1-2020 • Aceptado: 20-3-2020 • josedamiaorodrigues@campus.ul.pt 
LAS SOCIEDADES que se desarrollaron en las diferentes islas de las Azores desde los inicios de su ocupación humana reprodujeron en lo esencial la configuración de la matriz ibérica (Rodrigues, 2005). No obstante, están pendientes de esclarecimiento numerosas cuestiones debido a la escasez de fuentes que nos podrían ayudar a conocer el sistema organizativo de las primeras generaciones de pobladores. Por este motivo, y aunque se ha ido localizando documentación dispersa, es frecuente recurrir a la crónica más antigua de que disponemos para las Azores, la del sacerdote Gaspar Frutuoso (1522-1591), que nos permite acceder a información de finales del Cuatrocientos y comienzos del Quinientos (Rodrigues, 2015b). A pesar de su reconocida importancia, la narración frutuosiana no trata de igual modo todas las islas, privilegiando, de hecho, las de São Miguel y de Santa Maria en detrimento de las de los actuales grupos central y occidental. Además, debemos señalar que el texto original sufrió algunas mutilaciones, lo cual nos priva del acervo informativo contenido en los folios desaparecidos (Rodrigues, 1978, pp. XX-XXII). De este modo, cuando contemplamos los diversos microcosmos insulares que se organizaban alrededor del poder concejil y buscamos las fuentes que nos permitirían trazar las líneas maestras de la historia local, comprobamos que la documentación municipal en el archipiélago surge principalmente a partir de mediados del Quinientos con contadas excepciones.

La villa de Horta, en la isla de Faial, no es ajena a este panorama, por lo que resulta imposible realizar un seguimiento de las rutinas administrativas a causa de la desaparición de la documentación municipal anterior al siglo XVII y el mal estado o la interrupción de las series documentales disponibles. Esto dificulta la reconstrucción tanto de las prácticas del gobierno de la república como de los procesos que, a semejanza de lo sucedido en otras asambleas del reino, de las islas y del imperio, llevaron a una disminución del número de individuos y familias participantes en el ejercicio del poder municipal en esta villa isleña. De igual modo, esta laguna nos impide conocer las eventuales cribas existentes dentro del grupo de poder y sus consecuencias en momentos de crisis como, por ejemplo, durante la compleja coyuntura de 1581-1583 (Valladares, 2010). Gracias a la descripción de Gaspar Frutuoso, sabemos que la confluencia de los actores y de los linajes en Faial no habría sido uniforme y se habría registrado un acentuado nivel de conflictividad, aunque se puede considerar que, de modo general, la población habría permanecido expectante ante la evolución de los acontecimientos (Arquivo dos Açores, 1981, vol. IV: 318-322).

Los condicionantes expuestos, además de otros que se podrían mencionar, no nos impiden sin embargo afirmar que el modelo social implantado en las Azores, que afectó al conjunto del archipiélago desde mediados del siglo XV hasta inicios del XIX, reprodujo en lo esencial una concepción corporativa de la sociedad. Esta se reflejaba en el léxico sociopolítico estamental y en las categorías tradicionales entendidas como 
consecuencia de la naturaleza de las cosas — el orden creado por Dios - y legitimadas por el derecho, que preservaba la separación básica entre nobles y plebeyos, privilegiados y no privilegiados. Una separación que se basaba en la condición — estatus, «estado»— o cualidad de las personas, en la posesión de la tierra y en el ejercicio de cargos públicos, que exigían y proporcionaban honor, por lo que de este modo quedaba excluida la mayor parte de la población del acceso a ese medio de promoción social (Rodrigues, 2005, 2008; Sousa, 2008). Es esta visión del tejido social la que se deduce de una observación de Gaspar Frutuoso a propósito de la creación de una compañía de aventureros en Faial a finales del Quinientos por iniciativa de Gomes Pacheco de Lima, provedor-mor de las fortificaciones en la coyuntura «de la alteración de las islas» ${ }^{1}$, es decir, en los años inmediatos a la proclamación de Felipe II como rey de Portugal. Aquel notable, «hombre de gran discreción y prudencia, y de tanta nobleza y buena condición», dirigió una compañía creada por él «donde se incorporaron casi todos los mejores de la isla, sc., la mayoría del ayuntamiento, el almojarife y los clérigos» (Frutuoso, 1978, pp. 280-281). De manera inequívoca, en el léxico de su época, el clérigo de São Miguel señaló que «los mejores de la isla», la sanior pars, se encontraban en el gobierno municipal, en la administración periférica de la corona - en este caso en una estructura de la fiscalidad regia: el almojarifazgo- y en la Iglesia. Es decir, estos ejercían los oficios que proporcionaban y exigían honor y eran por lo tanto controlados por la nobleza local y otros cuerpos privilegiados como el clero, lo cual permitía a las familias dominantes asegurar la reproducción social no biológica por vía de la carrera eclesiástica.

\section{Los nobles de la gobernanza de la villa de Horta (siglos XVII-XVIII): una breve caracterización}

Los grupos familiares que en su mayoría componían la nobleza de la gobernanza local constituían el principal grupo de poder y se organizaban según el modelo de la «casa», controlando la posesión de la tierra y evitando su fragmentación y dispersión mediante el recurso a prácticas de vinculación (Rodrigues, 2003 [2004], II). La documentación existente confirma esta práctica y revela que también en el caso del eje Faial-Pico mujeres y hombres, integrantes del gobierno municipal y clérigos habían instituido capellanías y mayorazgos que, a finales del Antiguo Régimen, se concentraban en un escaso número de casas².

La traducción de las citas que figuran a lo largo del texto es obra del traductor.

Biblioteca Pública e Arquivo Regional João José da Graça (en adelante BPARJJG), Horta, Gobierno Civil, registro vincular, 15 libros. El fondo del Gobierno Civil no estaba organizado ni clasificado en el momento de nuestra investigación (noviembre del 2011 y marzo del 2012), la cual nos ha per- 
Las fuentes municipales conservadas permiten confirmar la continuidad de los linajes en el ejercicio de los oficios de la administración regia, la coincidencia de apellidos entre aquellos que ocupaban cargos en el ayuntamiento, la aduana y el almojarifazgo de Horta y, de modo general, la circulación de los miembros de las familias de la gobernanza local por los puestos de poder, concretamente por las patentes superiores de las compañías de ordenanzas. El linaje y la sangre eran los elementos esenciales en la configuración de las elites de poder: la sangre era un «organizador social» (Hernández Franco y Rodríguez Pérez, 2013, p. 350). Sin embargo, debemos evitar cualquier lectura que defienda que los grupos de poder local eran estancos y que estaban totalmente cerrados al exterior. De hecho, existía una práctica de reproducción social y política que se manifestaba en la existencia de «dinastías» familiares, que configuraba un sistema casi hereditario en el gobierno de las tierras, y la legislación de la monarquía contribuyó igualmente al reforzamiento de esa dinámica endógena. De todos modos, es también cierto que las gobernanzas se fueron renovando en función de las diversas coyunturas y que los actores históricos supieron, en la medida de sus posibilidades, aprovechar las circunstancias que les eran más favorables.

En este contexto, la incorporación de Portugal a la monarquía hispánica representó para muchos individuos una coyuntura que ofrecía un abanico de oportunidades de promoción social y política. Al reino de Portugal y, consecuentemente, a las Azores — en este caso tras la conquista de la isla Terceira en 1583 (Meneses, 1987) — llegaron nobles y plebeyos, oficiales y soldados, tanto con sus respectivas familias como solteros, y muchos reclamaron después a otros parientes que se reunieron con ellos en las islas donde se asentaron logrando en ocasiones una exitosa integración en las sociedades isleñas. Las crónicas coetáneas relatan algunas de esas trayectorias y el cruce de las fuentes narrativas con las archivísticas permite confirmar su gran éxito.

¿Cuántos eran los hombres que constituían el gobierno? Para el período comprendido entre inicios del siglo XVI y comienzos del XIX no disponemos de las listas de las elecciones trienales con los nombres de los candidatos, por lo que desconocemos su número exacto en cada año. Podemos, sin embargo, recurrir a las fuentes municipales para hacernos una idea aproximada de cuál sería la dimensión del grupo

mitido identificar y «rescatar» los quince libros del registro vincular. Por las facilidades concedidas y por el apoyo prestado, queremos aquí expresarle nuestro agradecimiento al director de la Biblioteca Pública e Arquivo Regional João José da Graça, Dr. Luís San Bento, y a los restantes técnicos superiores y funcionarios. Al igual que en el caso de São Miguel, el núcleo existente en el Arquivo Nacional da Torre do Tombo relativo al registro vincular de Horta está incompleto, ya que falta la referencia a los vínculos administrados por António Bettencourt Cardoso Machado (Pimenta, 1932: 29-30). Sobre las genealogías de las familias de Faial y Pico y, en particular, la ascendencia de los administradores de los vínculos referidos, se recomienda consultar el importante estudio de Forjaz y Mendes (2009). 
de poder local tomando como referencia el número de los presentes en determinadas reuniones. Debido a su importancia, estas contaron con la participación del cuerpo de oficiales del ayuntamiento, de los miembros del gobierno y de la nobleza de la isla, tanto eclesiástica como secular, como se indica en la reunión del 1 de junio de 1759, efectuada para combatir a los «atravessadores» ${ }^{3}$. Por lo tanto, tendremos en cuenta algunas reuniones que, por la relevancia de los asuntos a tratar, nos ofrecen datos sobre el número de individuos integrantes de la gobernanza de la isla de Faial.

El 22 de enero de 1600 tuvo lugar la elección de los guardas-mores da saúde ${ }^{4}$, de la que se conserva la declaración en auto firmado por quince «hombres de la gobernanza $\rangle^{5}$. Sin embargo, en traslado de la reunión celebrada en el ayuntamiento el 10 de mayo de 1632, además del corregidor Manuel Figueira Delgado, del oidor eclesiástico Gregório Dutra Machado y del escribano del almojarifazgo Francisco Viegas da Fonseca, en sustitución del sargento-mor, estuvieron presentes y se registraron veinte nombres de «personas nobles de la gobernanza» ${ }^{6}$. Décadas más tarde, en la junta convocada por los oficiales municipales el 16 de junio de 1670 para proponer la elevación de la localidad de Horta a ciudad, además de la presencia del capitão-mor y del sargento-mor, la nobleza local compareció en masa reconociendo la importancia de la reunión, firmando el auto cincuenta y seis sujetos 7 . A inicios del Setecientos, en pleno contexto de la Guerra de Sucesión española, encontramos una nueva y concurrida reunión. El 3 de julio de 1709, los oficiales municipales convocaron a la nobleza y al pueblo para tomar una decisión sobre el tributo ofrecido para el pago de dos compañías asalariadas. Sin considerar las siete firmas de los juízes dos oficios, pero contando la del capitão-mor y la del sargento-mor, son más de setenta las firmas registradas ${ }^{8}$. En una nueva junta, celebrada el 4 de mayo de 1736, se reunieron los oficiales del

BPARJJG, Arquivo da Câmara da Horta (en adelante ACH), Livros do Registo, Livro 9 (1751-1770), fls. 137-140 v, maxime fl. 140, para a referência.

$4 \quad$ Oficial perteneciente a las élites locales encargado del control sanitario en un puerto marítimo (N. del T.).

5 BPARJJG, ACH, Livros do Registo, libro 4 (1641-1651), fols. 92-94. Esta declaración en auto está registrada en una petición del escribano municipal António de Medina Picanço dirigida al juez ordinario en ejercicio, el capitán Francisco Gil da Silveira, con fecha del 20 de marzo de 1645. El escribano tenía en su poder los libros del gobierno municipal, entre los que se encuentra uno de 1600 con esta declaración, pretendiendo inscribirla en los libros de registro «por ser pocos y los del gobierno municipal muchos». BPARJJG, ACH, Livros do Registo, libro 4 (1641-1651), fols. 24v-26v.

BPARJJG, ACH, Livros do Registo, libro 6 (1665-1687), fols. 41-42v; Macedo, 1871, vol. I: 182 y 414-415, documento n. ${ }^{\circ} 37$.

8 BPARJJG, ACH, Livros de Vereações, libro 4 (1709), fols. [22]-24. Por lapsus, el escribano registró dos veces el fol. 21. Este libro se encuentra en muy mal estado: algunos folios son casi ilegibles y en otros hay fragmentos de difícil lectura por encontrarse la tinta muy borrada, por lo que la identificación de algunas firmas resulta problemática. 
ayuntamiento, el capitão-mor de Faial, la nobleza local, las autoridades conventuales - el padre rector Tomás Coutinho, el prefecto Teotónio Rodrigues da Câmara y el padre superior del convento del Carmen-, a los que se sumaron el capitão-mor de São Roque y el sargento-mor de Madalena con el fin de «consultar la solución» para obviar la prohibición real de navegar desde Faial hasta Brasil, cuestión vital para la economía isleña (Rodrigues, 2003 [2004], I, pp. 150-163; Rodrigues, 2016). En esta reunión se identifican cincuenta nombres de la élite local, incluido el escribano del ayuntamiento9 . Para concluir, a finales del Antiguo Régimen, con ocasión de la elaboración de la lista de los candidatos a concejal que debería de someterse al Desembargo do $\mathrm{PaçO}^{10}$, el total de nombres inscritos en el trienio 1794-1796 era de treinta y tres ${ }^{11}$. Si tomamos como indicador las presencias y las firmas en algunas de las reuniones más concurridas celebradas en el ayuntamiento de Horta — las juntas de 1670, 1709 y 1736- diríamos que durante el período moderno la cantidad de nobles en la gobernanza osciló entre las dos y las cinco decenas de individuos, aunque el número de participantes en los actos políticos estaba más próximo al umbral inferior.

Si integramos estas cifras en el conjunto demográfico de la isla de Faial, según los datos conocidos para los siglos XVII y XVIII y teniendo en cuenta que en el período analizado la población de la isla aumentó, a pesar de las crisis, las epidemias y las migraciones, pasando de tener cerca de 13.300 habitantes en 1695 a más de 16.600 en $1747^{12}$, podemos concluir que estamos ante un porcentaje muy reducido de individuos y familias, lo que se traduce en el estrechamiento del grupo y en la elitización del gobierno local durante el Antiguo Régimen.

A pesar de existir distintas formas de acceso al grupo de poder local, el reconocimiento definitivo de pertenencia se producía con la selección del nombre de un individuo como candidato ${ }^{13} \mathrm{y}$, sobre todo, con su elección o nombramiento efectivo para un cargo municipal. En relación con los siglos del Antiguo Régimen, el proceso electoral es bien conocido en líneas generales. En el período cronológico aquí estudiado los oficiales del ayuntamiento de Horta fueron elegidos de tres modos distintos: en el caso de los jueces ordinarios, los ediles y el procurador municipal rigió inicialmente el sistema tradicional de pelouros — definido por D. Juan I en 1391—y, posteriormen-

BPARJJG, ACH, Livros de Vereações, libro 7 (1731-1736), fols. 126-128v.

Tribunal superior de justicia del reino portugués entre los siglos XVI e inicios del XIX (N. del T.). Arquivo Nacional da Torre do Tombo (en adelante ANTT), Desembargo do Paço, repartição da Corte, Estremadura e Ilhas, marzo de 1672, doc. 9, Horta, auto del 5 de diciembre de 1793.

12 Se produjo un ligero descenso en 1776, pero aun así la población se mantuvo por encima de los 16.000 habitantes (Madeira, 1999; Pinto, Rodrigues y Madeira, 2001; Rodrigues, 2012a).

13 BPARJJG, ACH, Livros do Registo, libro 8 (1717-1751), fols. 262-262v. Decreto del 22 de diciembre de 1747 para la elección trienal de 1748,1749 y 1750 en que se convoca a los integrantes de la gobernanza a escoger a seis personas como candidatas el 27 de diciembre. 
te, el de pautas régias, aunque solo para los ediles y el procurador; y respecto a los escribanos, operó el nombramiento en propiedad del cargo o la promoción temporal. Aunque el método de pelouros, en apariencia aleatorio, pretendía ser un medio para evitar los desórdenes derivados de la elección de los cargos municipales, se reveló como un mecanismo para seleccionar a quienes podrían integrar las listas municipales, un instrumento eficaz al servicio de las redes relacionales fundamentadas en los lazos familiares (Coelho y Magalhães, 1986, pp. 43-44 y 141-144; Hespanha, 1986, I, pp. 495-497; Hespanha, 1989, pp. 295-297; Silva, 1988, I, pp. 382-394; Soares, 1995, II, pp. 1479-1482; Meneses, 1993, pp. 80-129). En la villa de Horta este fue el método vigente «desde la creación de la gobernanza de esta isla» ${ }^{14}$ hasta las reformas introducidas en el reinado de D. José.

Una vez realizadas las elecciones para los ayuntamientos cada tres años, y divididas por tres bolas de cera - los pelouros - las listas con los candidatos para el trienio siguiente, la apertura anual del arca donde se guardaban los pelouros se llevaba a cabo en el ayuntamiento de Horta el 1 de enero. Identificados los candidatos electos, el escribano del ayuntamiento redactaba un certificado en el que se confirmaban los nombres que habían salido en el pelouro y ese documento era remitido luego al corregidor, donde este se encontrase, para que el oficial regio emitiese la respectiva carta de confirmación o carta de usança. Tras verificar la situación judicial de cada uno de los elegidos y el posible parentesco existente entre ellos, el corregidor emitía un certificado y después una carta que les concedía el derecho a todos o solo a algunos de ejercer los cargos municipales. En el caso de existir impedimentos o cuando uno de los nombrados se encontraba ausente o ya hubiese fallecido, se procedía a realizar una elección por votación.

Las cartas conocidas para el siglo XVII, y en menor número para el XVIII, nos ofrecen datos interesantes sobre el área geográfica de reclutamiento de los oficiales del ayuntamiento de Horta y de los motivos que impidieron a determinados individuos el ejercicio del cargo $^{15}$. En lo que se refiere a la procedencia de los oficiales municipales, la mayoría residían en la villa, donde se encontraba la sede del ayuntamiento. Otros residían en el término municipal: en Praia do Almoxarife, Ribeira dos Flamengos, Feteira, Castelo Branco, Cedros y, en menor número, en Farrobo, Ribeirinha, Pedro Miguel o Praia do Norte. En cuanto a los motivos que originaron los impedimentos, los corregidores señalaron siempre que algunos de los individuos habían sido objeto de autos de querella y no habían concluido los procesos; que habían sido condenados

14 Esta expresión procede de una carta de los oficiales del ayuntamiento de Horta dirigida al capitãomor de Faial, datada el 8 de junio de 1757. BPARJJG, ACH, Livros do Registo, libro 9 (1751-1770), fol. 94.

15 Para mediados del siglo XVIII, cf. Meneses, 1993, pp. 98-103. 
al destierro o que tenían un grado de parentesco próximo - dentro del cuarto grado-, un problema frecuente y general en los ayuntamientos del reino y del imperio, lo que les impedía tomar posesión. Encontramos impedimentos por motivos relacionados con la justicia en 1645, 1649, 1655 y $1697^{16}$ e incluso más tarde, en $1809^{17}$. Debemos añadir que aquellos a quienes les había sido vetado el acceso a la toma de posesión y juramento del cargo en un primer momento, siempre podían demostrar que eran inocentes y que la acusación había sido retirada o considerada infundada. En relación con los impedimentos por parentesco podemos citar, entre otros ejemplos, los casos sucedidos en 1647, 1663 - en este año en dos ocasiones, puesto que uno de los elegidos mediante votación era pariente del concejal más viejo, por lo que fue necesario realizar una segunda elección-, 1671 y $1672^{18}$.

Si los problemas de justicia tenían su origen en la microconflictividad propia de las sociedades tradicionales preindustriales y en comportamientos individuales menos adecuados al ejercicio del cargo, en el caso de los parentescos eran resultado de una práctica continuada de las élites locales. En efecto, en los planos social y político la preferencia por el mercado matrimonial constituido por los propios grupos de poder local y traducida en alianzas endogámicas y consanguíneas condujo a un progresivo estrechamiento de estos, frente a una renovación muy limitada, a veces casi inexistente, de los cuerpos políticos urbanos. En territorios de menor dimensión, como es el caso de las islas, el reforzamiento de dichas dinámicas fue mayor. A propósito de lo que hemos observado para São Miguel en el siglo XVIII e inicios del XIX, con una circulación y renovación menor de los cargos de los ayuntamientos a medida que descendemos en la jerarquía de la red urbana de la isla, creemos que este escenario estaría propiciado por lo que consideramos «un efecto isla» (pequeña dimensión, movilidad geográfica limitada y acceso a menos recursos del centro) (Rodrigues, 2003 [2004], I, pp. 438-439).

Esta eventual especificidad carece aún de una mejor fundamentación, pero es innegable, sin embargo, que desde finales del Quinientos las redes de parentesco estaban consolidadas de tal forma en los archipiélagos de Madeira y de las Azores que resultaba complicado cumplir lo dispuesto en las Ordenanzas del Reino. De este modo, ante la necesidad de asegurar el gobierno cotidiano de los pueblos y la colaboración

\footnotetext{
16 BPARJJG, ACH, Livros do Registo, libro 4 (1641-1651), fols. 101v-106 (1645), fols. 157-158v y fols. 158v-160 (1649); libro 5 (1651-1666), fols. 36v-38v (1655); libro 7 (1688-1716), fols. 49v-51v (1697).

17 BPARJJG, ACH, Livros de Vereações, libro 14 (1801-1810), fols. 240v-242 y 253-253v.

18 BPARJJG, ACH, Livros do Registo, libro 4 (1641-1651), fols. 129v-133v y fols. 136-137v (1647); libro 5 (1651-1666), fols. 196-200 y fols. 202v-205v (1663); libro 6 (1665-1687), fols. 46v-50 (1671) y $65-67 \mathrm{v}(1672)$.
} 
de las élites locales, la corona elaboró legislación adaptada a las circunstancias insulares. En 1590, Felipe II autorizó la admisión de parientes por afinidad en las listas municipales, pero fue la provisión de D. Alfonso VI del 12 de septiembre de 1661 la que determinó que los corregidores dispensasen los grados de parentesco, por lo que los cargos municipales y de justicia podían estar ocupados por parientes de segundo grado en adelante (Rodrigues, 1994, p. 140). En la villa de Horta este diploma fue registrado el 12 de octubre del mismo año ${ }^{19}$ y lo sería igualmente en otros municipios de las Azores ${ }^{20}$.

Finalmente añadiremos que, incluso tras la elección —o después de 1766 tras la recepción de la lista del Desembargo do Paço-, un cargo podía solicitar su sustitución por motivo de enfermedad, incompatibilidad para desempeñar el cargo o ausencia, y también el propio ayuntamiento podía exponer la necesidad de cambiarlo, tal y como sucedió en 1773. En el pleno del 17 de noviembre de ese año se considera que el procurador municipal, el licenciado José Pinto, faltaba demasiado a las reuniones y no acompañaba a la corporación municipal en otras ocasiones - aunque se hubiese justificado con el hecho de ser cirujano habilitado y de tener que recorrer toda la isla por trabajo- - por lo que se decide sustituirlo por el procurador anterior Bernardo de Sousa da Fonseca ${ }^{21}$. Téngase en cuenta que esta sustitución no es consecuencia de la existencia de una situación de conflicto o de incapacidad física del mencionado José Pinto, sino tan solo al hecho de que, por desempeñar otra actividad, no podía cumplir con la que debería ejercer en el ayuntamiento.

A inicios de la segunda mitad del Setecientos, en el contexto de la creación de la capitanía general de las Azores por los diplomas del 2 de agosto de 1766 firmados por el rey, pero concebidos por Sebastião José de Carvalho e Melo, se modificó el sistema electoral de la ciudad de Ponta Delgada en la isla de São Miguel y de las principales villas del archipiélago. Uno de los objetivos de las reformas introducidas en las islas era la reafirmación de la jurisdicción regia y el control de la justicia y de los gobiernos

19 BPARJJG, ACH, Livros do Registo, libro 5 (1651-1666), fols. 167-168.

20 La provisión fue registrada en Ponta Delgada el 16 de marzo de 1662. En el siglo siguiente fue de nuevo inscrita en el libro de registros del ayuntamiento de la ciudad el 4 de abril de 1762 y, a petición de los cargos del ayuntamiento de Ponta Delgada en Ribeira Grande, el 21 de julio de 1803 — a partir de los traslados de Vila Franca do Campo del 17 de noviembre de 1661 y de Ribeira Grande del 22 de junio de 1682 - y, nuevamente, el 15 de octubre de 1803. Cf. Biblioteca Pública e Arquivo Regional de Ponta Delgada (en adelante BPARPD), Arquivo da Câmara de Ponta Delgada (en adelante ACPD), libro 115, fols. 26v-27; libro 116, fols. 334-335 y fol. 121, fols. 75-77v. Fue también registrada en el ayuntamiento de Angra. Cf. Biblioteca Pública e Arquivo Regional de Angra do Heroísmo (en adelante BPARAH), Arquivo da Câmara de Angra do Heroísmo (en adelante ACAH), libro 4, fols. 121-121v.

21 BPARJJG, ACH, Livros de Vereações, libro 12 (1766-1778), fols. 159-159v, 17 de noviembre de 1773. 
locales. En este sentido iban encaminadas la recuperación de la corregedoria de São Miguel y Santa Maria, la creación de puestos de juiz de fora en gran parte de las islas y la aplicación del sistema de pautas régias en Ponta Delgada y en las principales villas (O Códice 529-Açores do Arquivo Histórico Ultramarino, 1988, pp. 23-27; Meneses, 1993, 1995a; Rodrigues, 2006).

En pleno contexto de reformas, la creación de una nueva configuración políticoadministrativa en las islas, con una alteración en las escalas de poder adaptada a las especificidades locales, constituyó sobre todo una pieza esencial de la estrategia política del conde de Oeiras para las Azores, aunque aquella hubiese representado un reconocimiento de la importancia de algunos ayuntamientos y hubiese contribuido al prestigio de las respectivas élites ${ }^{22}$. En esta situación, el primer juiz de fora de Horta, el bachiller José da Rocha Dantas e Mendonça, se presentó ante la corporación municipal y tomó posesión de su cargo el 15 de agosto de $1767^{23}$, lo que supuso el inicio de una nueva fase en el gobierno de esta villa. En este escenario de múltiples poderes y jurisdicciones concurrentes, la documentación local indica que, por lo menos en el plano formal, hasta finales del siglo XVIII se registró de manera general un clima de buen entendimiento entre los juizes de fora nombrados por la corona y la nobleza de Faial que servía los oficios de la república (Rodrigues, 2012b).

En lo relativo a las candidaturas municipales, la obligatoriedad de presentar en el Desembargo do Paço las listas elaboradas localmente para la aprobación de los nombres en ellas incluidos, pretendía introducir el control del poder central sobre las noblezas municipales. Pero si la nueva división comarcal y los puestos de letras permanecieron hasta el liberalismo, el resultado final estuvo lejos del objetivo inicial en lo tocante al control de las élites locales por vía de la intervención del Desembargo do Paço en la elección de los cargos municipales. De hecho, la distancia en relación al centro político y la discontinuidad geográfica existente en las Azores acentuaban aún más la dificultad que se le presentaba a la monarquía para ejercer un control efectivo de las periferias. A pesar de la amplia jurisdicción otorgada a los capitanes generales, ni estos agentes de la monarquía ni otros - los corregidores - fueron capaces de aplicar íntegramente el programa reformista a lo largo de la segunda mitad del siglo XVIII, por lo que, de manera general, las gobernanzas locales mantuvieron su autonomía.

En la larga duración, la práctica de alianzas endogámicas y consanguíneas, que condujo al progresivo cierre de los cuerpos políticos urbanos y a su muy limitada renovación, ayuda a comprender la resistencia de estos grupos de las noblezas locales.

\footnotetext{
22 Para una síntesis de los contextos de creación de jurisdicciones letradas en el imperio portugués y, en particular, de los juizes de fora, cf. Camarinhas, 2018.

23 BPARJJG, ACH, Livros de Vereações, libro 12 (1766-1778), fols. 56-56v.
} 
Todos los individuos identificados en el ejercicio de los principales cargos del ayuntamiento pertenecían al círculo de la nobleza municipal y así eran reconocidos en el ámbito local — e incluimos aquí a la vecina isla de Pico - y en lugares más distantes como la ciudad de Angra. Sin embargo, no se encontraban todos al mismo nivel y era posible registrar diferencias de estatus, honor, prestigio y riqueza. Pertenecer a la principal nobleza de la tierra era condición sine qua non para acceder a determinados puestos y, por ello, no es de extrañar que algunos hombres de la gobernanza hubiesen optado por la autopromoción en las solicitudes remitidas al capitán general o a la corte. En el contexto de los conflictos que rodearon a las facciones locales en torno a las elecciones para sargento-mor a inicios de la década de 1770, uno de los candidatos fue António Teles de Utra Machado, que alega en su solicitud su nobleza y su patrimonio. El capitán general se refirió al susodicho, en una información sobre este asunto fechada el 3 de marzo de 1779, diciendo que «aunque sea hombre de bien no es, así y todo, de la principal nobleza de la isla de Faial». En cuanto a lo que afirmara el propio António Teles de Utra Machado acerca del modo en que era tratado en público, los datos de que disponía el capitán general confirmaban, al contrario de lo que el interesado había declarado, que tenía un «tratamiento muy común y ordinario» ${ }^{24}$. Ser hombre de bien no significaba tener estatus de principal.

A este respecto, el auto del 5 de diciembre de 1793, relativo a la elaboración de la lista de candidatos a concejal para el trienio 1794-1796, revela la diversidad de estatutos y jerarquías que se podían detectar entre la nobleza de la gobernanza de Faial. De los treinta y tres candidatos, siete eran hidalgos de la Casa Real y uno tenía el hábito de la Orden de Cristo, además de aparecer otro individuo que no poseía el foro de hidalgo, pero era hijo y nieto de hidalgos de la Casa Real; veinte fueron registrados como integrantes de la nobleza local o de otros municipios; diez eran «de las familias principales»y, de estos, uno, el alférez de las ordenanzas João Silveira Vila Lobos, de 32 años, se había casado por debajo de su nivel social25; once eran mayorazgos que vivían de la administración de sus vínculos; solo tres de los candidatos eran letrados, indicándose en relación a Manuel Inácio de Sousa, de 56 años, que era «actualmente negociante al por mayor en esta isla» ${ }^{26}$; otros tres eran oficiales de las ordenanzas, pero uno era también letrado; dieciocho eran militares del tercio

\footnotetext{
24 Arquivo Histórico Ultramarino (en adelante AHU), Conselho Ultramarino (en adelante CU), Açores, cx. 13 , doc. 6 .

25 ANTT, Desembargo do Paço, Repartição da Corte, Estremadura e Ilhas, marzo de 1672, doc. 9, Horta, auto del 5 de diciembre de 1793, fol. 22v: «y suponiendo que sea persona noble como se ha dicho antes, así y todo, se casó con una mujer de muy inferior y baja condición respecto a su categoría».

26 Idem, fol. $23 \mathrm{v}$.
} 
de auxiliares y, para finalizar, el alférez de 30 años del tercio auxiliar Estolano Inácio de Oliveira Pereira, hijo del negociante al por mayor João Inácio de Oliveira Pereira. El contexto descrito muestra las diferencias de estatus, de honor y de riqueza, que no solo se manifestaban entre los cuerpos de oficiales de un ayuntamiento y los de otro, sino también en el interior de cada grupo de poder local. Desde el punto de vista del análisis sociológico este es un aspecto a destacar: los integrantes de la gobernanza no constituían un verdadero grupo social y los individuos que componían las candidaturas de cada ayuntamiento no tenían todos igual origen social, un hecho que se reflejaba en las fronteras que delimitaban en cada microcosmos concejil la separación entre el grupo de la gobernanza y el resto de la población (Monteiro, 1996).

Los elementos referidos permiten efectuar otra lectura igualmente importante. La exposición sumaria que hemos realizado nos aclara, aunque de forma incompleta, que los estatutos y, consecuentemente, los recursos materiales y simbólicos se mezclaban y confundían, lo que desaconseja la adopción de criterios de clasificación social excesivamente rígidos y fundamentados en categorías propias de nuestra época (Cerutti, 1995; Fairburn, 1999, pp. 13-38 y 203-234). Por ejemplo, los capitães-mores de Faial, los Brum da Silveira Porras Taveira, eran a su vez hidalgos de la Casa Real, oficiales de las ordenanzas y mayorazgos. Tanto en las Azores como en el reino, las fuentes locales, concretamente las notariales, tendían a distinguir la administración vincular y la nobleza - «fulano, que vive de sus mayorazgos y de la primera nobleza de esta llamada ciudad $\gg{ }^{27}$ - y en este sentido, según observó Nuno Gonçalo Monteiro (1997, p. 350, nota 46), «la verdad es que la identificación de alguien en una lista por tener un vínculo constituía casi siempre un indicador de nobleza antigua». De esta manera, tal y como defendemos en otros trabajos, a pesar de la existencia de un «mundo común», de una cultura política holística, de un modelo social estructurante y de prácticas sociales compartidas, las lógicas sociales locales se imponían al referente general (Rodrigues, 2009). Además de las referencias universales, es necesario no olvidar que «la logique hiérarchique est locale par essence», por lo que las categorías y el respectivo uso social de estas deben ser evaluados en los contextos específicos en que se producen y ajustan las clasificaciones y las identidades («À propos des catégories sociales de l'Ancien Régime», 2005, p. 31), es decir, la realidad y el «saber local» (Clifford Geertz).

En el caso de las Azores, donde podemos identificar un «conjunto segmentado de oligarquías» a lo largo del período analizado (Sousa, 2008: 600), los estudios ya realizados revelan la importancia de conocer en profundidad las dinámicas sociales locales y el uso que los actores efectuaban del vocabulario y de los recursos a su al-

$27 \quad$ BPARPD, Cartório Notarial, Ponta Delgada, 321, Livro de Notas de los notarios Alexandre José de Barros e João Manuel de Faria (1800-1802), fols. 93v-94v, maxime fol. 93v. 
cance. En la cúspide de la jerarquía social se situaban los hidalgos de la Casa Real, correspondiéndole una posición principal a las casas de los capitães-mores y de los sargentos-mores de Faial. La consulta de la documentación municipal permite confirmar la importancia que estos individuos atribuían al reconocimiento formal y a la publicitación de su foro a través de la copia de las provisiones de dicho foro en los libros de registro ${ }^{28}$. De igual modo, fueron registrados blasones de armas, un símbolo de distinción social que no estaba al alcance de todos y que, en un contexto de disputa por la mayor calidad y estima social, se configuraba como un instrumento central en la estrategia de las casas y de los individuos ${ }^{29}$. Por debajo del escalón superior de la nobleza de la isla se situaba la mayor parte de los hombres de la gobernanza, varios de ellos residentes fuera del núcleo urbano de Horta y que, en el trascurso de sus trayectorias vitales, sirvieron solamente una o dos veces los oficios de la república. Para finalizar, debemos destacar el hecho de que los hombres de negocios están prácticamente ausentes del grupo de poder local, a pesar del reconocido valor del puerto de Horta y de la importancia del comercio atlántico del vino y del aguardiente de Pico, sobre todo en los mercados de Brasil, América del Norte y las Antillas (Duncan, 1972; Meneses, 1995b).

\section{Poder y conflictos en la villa de Horta: facciones, elecciones y cuestiones de jurisdicción}

Las asimetrías aquí expuestas estuvieron ciertamente presentes en los conflictos interpersonales y entre facciones. Las disputas alrededor del poder y los problemas de jurisdicción que marcaron la vida municipal en Faial eran también una lucha por un mayor protagonismo social y político. De este modo, a lo largo de los siglos XVII y XVIII y en las primeras décadas del siglo XIX, a pesar de la imagen que se pretendía transmitir de cohesión del cuerpo político de la república, emergen en la documentación las «rivalidades individuales y de grupo y las sospechas de soborno», situaciones

28 Cf., entre otros ejemplos, BPARJJG, ACH, Livros do Registo, libro 7 (1688-1716), fols. 8v-9 (sargento-mor Jorge da Terra da Silveira, 3 de agosto de 1688), fols. 9-9v (reverendo licenciado Francisco de Brum da Silveira, 3 de agosto de 1688), fols. 10-10v (Estevão de Brum da Silveira, 3 de agosto de 1688), fols. 10v-11 (capitán Manuel de Brum da Silveira, 3 de agosto de 1688), fols. 7676v (capitán Bernardo Soares Teixeira, 22 de junio de 1699), fols. 161v-162 (Jacinto Manuel Brum da Silveira, 4 de noviembre de 1705) y fols. 162-162v (José da Terra e Silveira de Mendonça, 2 de noviembre de 1705); libro 8 (1717-1751), fols. 23-23v (capitán Matias da Silveira Pereira, 22 de abril de 1719); libro 9 (1751-1770), fols. 39-39v (Jerónimo Brum da Silveira, 30 de mayo de 1754); libro 10 (1766-1798), fol. 225v (Manuel Inácio Brum do Canto, natural de Angra, 7 de enero de 1789) y fol. 226 (José Francisco da Terra Brum de Noronha, 30 de abril de 1794).

29 Cf., entre otros ejemplos, BPARJJG, ACH, Livros do Registo, libro 9 (1751-1770), fols. 52-54 (José Rodrigues Goulart Whitton, 15 de octubre de 1754). 
también comunes en los demás ayuntamientos del reino, de las islas y de ultramar (Meneses, 1993, pp. 114-126, maxime pp. 119-121). Las divisiones y los conflictos detectados comprenden todo el Antiguo Régimen, pero la consulta de la documentación indica que habrían tenido particular gravedad en la segunda década del Setecientos, continuando después en las décadas de 1730 a 1770, con mayor relevancia en los años 1747-1748, 1753, 1756, 1764, 1772-1773 y, finalmente, en los últimos años del siglo. Entonces se encontraba en el epicentro de los acontecimientos el juiz de fora de Faial, el bachiller José Joaquim Botelho de Almeida, que fue nombrado por carta el 9 de marzo de 1795 y tomó posesión del cargo en la casa consistorial de Horta el 13 de julio ${ }^{30}$. En los albores del nuevo siglo nada había cambiado y las acusaciones de fraude en las elecciones de los oficiales de las ordenanzas continuaron produciéndose (Costa, 2005, I, p. 144).

Si tenemos en cuenta la tendencia a la ósmosis que se verifica en los siglos XVII y XVIII entre los oficiales del ayuntamiento y los de las compañías de ordenanzas - lo que llevó a Joaquim Romero Magalhães (1988: 339) a considerar a los vereadorescapitães como «las piezas maestras del edificio social»—, la indicación de una patente militar de las ordenanzas constituye un indicio de que estamos ante un sujeto social que formaba parte de la élite del poder local, es decir, de los «señores de la república». Así, debido a la importancia que estos puestos tenían en la definición de las jerarquías en las sociedades tradicionales del Antiguo Régimen, la búsqueda de mayor poder o la defensa de una posición social consolidada situaban con frecuencia a los oficiales de las ordenanzas en el epicentro de los conflictos, a los que no eran inmunes los capitãesmores y los sargentos-mores. También fue así en la Horta del Setecientos. A finales de 1714, el corregidor de la comarca emitió un mandato desde Angra, dirigido a los jueces ordinarios y demás oficiales del ayuntamiento de Horta, donde daba cuenta de que mal había tomado posesión de su cargo,

me foi publiCo e noto // e notorio o notauel esCandalo que não Só nesa Jlha mas em todas as mais desta ComarCa tem Cauzado as parCialidades inquietasoens, e perturbasoens desa Jlha Sendo a Cauza dellas muitas das pesoas prinCipais de Respeito e jurisdisão, que deuião ConCiliar o SoSego dos pouos e Com a boa administrasão da justisa ConSerua los em pas e ConCordia por Ser asim Conueniente ao bem Comum, Seruiso de Deus e de sua Magestade que Deus guarde ${ }^{31}$.

$30 \quad$ Este caso está bien documentado en las fuentes de la época y un importante proceso se encuentra en AHU, CU, Açores, cx. 29, doc. 6. Cf. Rodrigues (2012b).

31 «Fue público y notorio el notable escándalo que no solo en esa isla, sino también en las restantes de esta comarca, han provocado la configuración de facciones, desasosiegos y perturbaciones, siendo la causa de ellas muchas de las personas principales de respeto y jurisdicción que debían conciliar 
En un lenguaje que expresa los valores más importantes de la monarquía barroca en el contexto de la cultura política del Antiguo Régimen, el magistrado regio denunciaba que la ausencia de paz y la perturbación del bien común, del servicio a Dios y al rey se debían a «personas principales de respeto y jurisdicción», es decir, individuos de la élite local que se encontraban en el ejercicio de sus oficios. El corregidor afirmaba que había sido informado de que los disturbios referidos habían aumentado «con repetidos procesos de motines y levantamientos» y eran promovidos por los «cabecillas» de las facciones enfrentadas, unos contra otros «sin más orden u obligación que el deseo de venganza ${ }^{32}$. Ante este escenario, ordenaba a los jueces ordinarios y a los oficiales del ayuntamiento de Horta que, tan pronto como tuviesen conocimiento del contenido de su mandato, suspendiesen todos los procesos y autos en curso relacionados con las perturbaciones y levantamientos hasta su llegada a Faial. En Horta, una vez abierta la orden, el consistorio fue notificado de su contenido.

A pesar de las intenciones del corregidor, este clima de agitación y de conflicto prosiguió y los ecos de los graves enfrentamientos existentes en la isla llegaron a la corte, lo que suscitó la intervención del Consejo de Guerra al estar implicados el capitão-mor y el sargento-mor de Faial. En el seguimiento de un requerimiento dirigido al Consejo de Guerra por el ayudante José Furtado, que se quejaba de haber sido puesto en prisión en los calabozos de la fortaleza de Santa Cruz por orden del capitão-mor António da Cunha e Silveira «con indecencia a su persona y al puesto que ocupa», en la carta real del 27 de octubre de 1714 enviada por esta institución se ordenaba al sargento-mor Jorge da Terra e Silveira que liberase al preso ${ }^{33}$.

Esta decisión ciertamente no contribuyó a apaciguar los ánimos de las partes y las facciones mantuvieron a la villa bajo el efecto de su contienda, que llegó hasta el propio ayuntamiento. Ambos oficiales, el capitão-mor y el sargento-mor, recibirían una orden real para abandonar la isla y en substitución del primero sería nombrado en 1716 el sargento-mor del castillo de Angra, Francisco Lopes Penteado ${ }^{34}$. Aún habrían de ser necesarias nuevas medidas para restaurar el orden en la villa de Horta. Otra carta regia del 19 de abril de 1717 ordenaba que el sargento-mor Jorge da Terra e Silveira y los oficiales municipales abandonasen la isla durante un mes y, estando los rivales y «cabecillas» de las dos facciones en Lisboa, otra nueva orden del 21 de mayo disponía

la tranquilidad del pueblo con la correcta administración de justicia para mantenerlo en paz y concordia por ser conveniente al bien común, al servicio de Dios y de su majestad, que Dios la guarde». BPARJJG, ACH, Livros do Registo, libro 7 (1688-1716), fols. 171-172, maxime fols. 171-171v para la cita, mandato del 9 de octubre de 1714 .

32 Idem, fol. $171 \mathrm{v}$.

33 Idem, fol. $172 \mathrm{v}$.

34 Idem, fols. 187-187v. 
que «ambos elaboren y firmen una declaración de amistad y de perpetua tranquilidad», la cual sería firmada ante el auditor general de la gente de guerra ${ }^{35}$. Desconocemos si fue firmada y cuál sería su contenido, pero, aunque se hubiese formalizado esta declaración de «perpetua paz», no resulta difícil creer que las enemistades y las heridas abiertas aún hubiesen tardado bastantes años en cicatrizar.

Las cuestiones relacionadas con la jurisdicción militar continuaron provocando fricciones dentro del círculo de poder local. A finales de la década de 1750 tenemos constancia de un nuevo conflicto a partir de una carta del Consejo de Guerra dirigida al sargento-mor Jorge da Cunha e Silveira. El Consejo se extrañaba de que el sargento-mor se hubiese dirigido al gobierno municipal para informar sobre las personas que podrían desempeñar el puesto de capitán de la fortaleza de Boa Luz cuando «ante la falta de capitão-mor de la isla de Faial no le correspondía su gobierno», sino a un capitán de infantería o de artillería a sueldo ${ }^{36}$. Pero el sargento-mor no era el único involucrado en el proceso y un albalá dirigido al juez ordinario José Francisco de Terra Brum e Silveira así lo verifica. Este notable había tomado posesión y jurado el cargo el 4 de marzo de $1758{ }^{37}$ y poco después ya estaba tomando decisiones sobre materia de jurisdicción militar. Por este motivo fue recriminado en el albalá del 6 de noviembre de ese año, en el que se le ordenaba que se abstuviese «del procedimiento existente a respecto del mando de esta isla». En el mismo documento se indica que habían apoyado al sargento-mor el alférez a sueldo João Inácio Borges de la Câmara y el ayudante Luís de Sá Pereira Camelo «con la finalidad de conservar en el mando al sargento-mor» ${ }^{38}$.

Las situaciones de tensión y de conflicto abierto marcaron la vida política y social de Horta en las décadas de 1750, 1760 y 1770, con diversas sospechas, sobornos y obstáculos en las elecciones para el ayuntamiento y para los puestos superiores de las ordenanzas (Meneses, 1993, pp. 119-121). Tras la institución de la capitanía general en 1766 y la consiguiente alteración del método de selección de los ediles y del procurador municipal, las disputas entre facciones sufrieron una relativa relajación. Sin embargo, esto no significa que las parcialidades hubiesen desaparecido; al contrario, los notables con mayor influencia o carisma continuaron movilizando las redes interpersonales para ampliar su poder y, en consecuencia, el de su propia casa. Y cuando no eran los propios integrantes de la gobernanza los que agitaban el día a día de Horta, algunos agentes de la corona más ambiciosos y ávidos de protagonismo ocupaban el centro de la arena política, como el ya referido juiz de fora José Joaquim Botelho de Almeida.

BPARJJG, ACH, Livros do Registo, libro 8 (1717-1751), fols. 14-16.

BPARJJG, ACH, Livros do Registo, libro 9 (1751-1770), fols. 123v-124.

Idem, fols. $107 \mathrm{v}-108 \mathrm{v}$.

Idem, fols. 124-125v. 
De hecho, este bachiller, que convivió con más de una corporación municipal, entre 1795 y 1798 quiso asumir el estatuto de almotacén mayor al nivel de la judicatura municipal; se involucró en asuntos del fuero eclesiástico; usurpó las atribuciones del proveedor de los resíduos y capellanías; invadió la jurisdicción de los oficiales de la Hacienda real y del gobernador del castillo de Santa Cruz, que era el gobernador militar de las islas de Faial y Pico; contribuyó a agudizar la división existente entre los miembros de la élite local que integraban el gobierno de la villa y apresó a diversos opositores (Serpa, 1915). Por lo tanto, no resulta sorprendente que el gobernador del castillo de Horta, Jerónimo Sebastião Brum da Silveira Frias Taveira e Neiva, hidalgo de la Casa Real y miembro de una de las principales familias de las Azores, en respuesta a los miembros del gobierno interino del archipiélago ante el nombramiento en 1798 de otro gobernador interino de las islas de Faial y Pico, se pronuncie sobre el comportamiento del juiz de fora y afirme que «los pueblos de aquella isla siempre sufrirán en silencio bajo el yugo de este ministro para evitar las calamidades mayores con que los amenazaba su irregular procedimiento en la administración de justicia» ${ }^{39}$. Muchas otras declaraciones y testimonios coetáneos presentan al magistrado regio como un actor central en el desencadenamiento de los conflictos al administrar justicia «con exorbitancia inaudita», absorber jurisdicciones ajenas y poner en práctica distintos tipos de violencia, conforme se puede leer en la atestación del 2 de junio de 1798 (Serpa, 1915, pp. 146-150).

Pero también contribuyó de nuevo a la inestabilidad que marca los años finiseculares en Horta la cuestión de las elecciones de los oficiales municipales, materia que seguía dividiendo al ayuntamiento. Con fecha del 27 de junio de ese mismo año de 1798, los miembros del gobierno municipal en ejercicio escribieron a la corte acerca de la lista del 12 de enero que, según estos, fijaba obstáculos a su ejecución. Alegaban que era «la cuarta lista procedente de la misma elección y que esto era una innovación contra la ley», por lo que hacían partícipe de este hecho a la reina a la espera de que esta ordenase lo que considerase. Contrariamente a lo que cabría esperar, la respuesta real, plasmada en la orden del 30 de julio expedida por el Desembargo do Paço, fue contundente: había que darle cumplimiento inmediato a la elección de los oficiales del gobierno municipal, aunque se tratase de la cuarta elección ${ }^{40}$.

A comienzos del siglo XIX, las líneas estratégicas de la política local no cambiaron. Los conflictos derivados del viraje de 1807-1808, a consecuencia de la invasión francesa de Portugal y del traslado de la familia real y de la corte a Brasil (Cardoso,

\footnotetext{
39 AHU, CU, Açores, cx. 27, doc. 41, citación al gobernador interino de las islas de Faial y de Pico, 27 de mayo de 1798.

40 BPARJJG, ACH, Livros do Registo, libro 10 (1766-1798), fols. 232v-233.
} 
Monteiro y Serrão, 2010), se dejaron sentir más en la isla Terceira, donde residía el capitán general. Pero a pesar de las tentativas del máximo representante de la monarquía en las Azores para imponerse a las noblezas isleñas, los gobiernos municipales habrían de mantener en gran medida una «elevada autonomía local informal» (Rodrigues, 2010; Sousa, 2008, p. 600). A modo de ejemplo, en lo que respecta a Horta y antes incluso de trasladarse la corte portuguesa a Brasil, la última lista enviada por el Desembargo do Paço el 9 de diciembre de 1806 fue abierta y registrada en el ayuntamiento el 11 de julio de $1807^{41}$. La lista siguiente solo llegaría en 1813 y el 27 de febrero de ese año se le da lectura a la provisión emitida por la junta creada en Río de Janeiro por albalá del 10 de julio de 1811 con los nombres de los nuevos oficiales ${ }^{42}$. Durante más de cinco años estuvo en ejercicio el mismo cuerpo de oficiales, y como algunos de ellos, en 1811 y 1812, estaban impedidos para servir, fueron llamados otros de años anteriores. Mientras, las fuentes revelan que las parcialidades continuaban operando en las reuniones del ayuntamiento en las que se pretendía atender al bien común de la población y al gobierno de la república, dando respuesta a la escasez de cereales que afectaba a la población o haciendo cumplir las órdenes reales relativas a la defensa de la isla. Sirva de ejemplo el caso de João Whitton Zarco da Câmara, edil segundo en 1809 , que fue excluido por decisión del juiz de fora al acusarlo de ser «jefe de partidos» y de fomentar intrigas, aunque el edil había conseguido demostrar su inocencia ${ }^{43}$.

\section{Breve conclusión}

En síntesis, en el caso de Horta, como en el de otros núcleos urbanos de las Azores, las familias principales - Brum da Silveira, Brum Terra, Pereira de Lacerda y Soares de Sousa entre otras — ostentaron una posición central en los ámbitos social y político local. Sus miembros formaron parte del gobierno municipal a lo largo del Antiguo Régimen y asumieron el liderazgo de las facciones que dividían al consistorio (Rodrigues, 2015a). Concentraron en sí el honor y el estatus, aunque a un nivel algo inferior al de las noblezas de las ciudades de Angra y Ponta Delgada ${ }^{44}$; monopolizaron el poder político y constituyeron la clase poderosa por excelencia —eran señores de tierras y, algunos, administradores de vínculos_- Su influencia continuó incluso

41 BPARJJG, ACH, Livros do Registo, libro 11 (1799-1808), fols. 190v-191; Livros de Vereações, libro 14 (1801-1810), fols. 196v-197.

42 BPARJJG, ACH, Livros de Vereações, libro 15 (1810-1819), fol. 47 (27 de febrero de 1813) y fols. 47v-48 (3 de marzo de 1813).

43 BPARJJG, ACH, Livros de Vereações, libro 14 (1801-1810), fols. 240v-242 (21 de enero de 1809) y fols. 253-253v (20 de mayo de 1809).

44 A inicios del siglo XIX, la indicación del estatuto y de la ocupación de los oficiales de las ordenanzas permite confirmar esa realidad. Cf. Costa 2005, I, p. 143. 
a lo largo del siglo XIX, con la adaptación al régimen liberal y el mantenimiento del poder a escala local. Además de las prácticas endogámicas y consanguíneas, que reforzaron la cohesión interna de la gente noble de la gobernanza local, seleccionaron la integración de nuevos elementos para asegurar de este modo un rejuvenecimiento selectivo del grupo.

A modo de conclusión, debemos recordar que los gobiernos municipales no estaban solos en el escenario político. Tenían que negociar y, a veces, disputar de forma abierta su autonomía y prestigio con otros poderes, siendo necesario destacar en el contexto geográfico que aquí nos interesa a los oficiales regios y al capitán de la isla con su oidor. La corona, con todo, necesitaba a la gente noble para gobernar los territorios, controlar al pueblo y cobrar los tributos; y, a su vez, las élites locales supieron obtener más privilegios, consolidar su posición y, cuando fue necesario, pidieron más recursos económicos para obras cuyo gasto superaba en gran medida los escasos recursos de las haciendas municipales.

De esta manera, en el arco cronológico aquí considerado, los marcos de 1766 —institución de la capitanía general de las Azores - y 1807-1808 — primera invasión francesa y traslado de la corte portuguesa a Río de Janeiro- no transformaron en lo esencial las prácticas de reproducción social y política de quienes integran las gobernanzas del archipiélago de las Azores y, en concreto, de la localidad de Horta. A pesar de la modificación del sistema electoral introducida en 1766, el control del ayuntamiento se mantuvo en manos de un reducido círculo de familias e individuos. De igual modo, si los meses siguientes al establecimiento de la corte en Río de Janeiro estuvieron marcados por «cierta anarquía en cuanto a la unión orgánica de dependencia de la capitanía general en relación al poder central» (Costa, 2005, I, pp. 93-94), los años siguientes a 1807-1808 evidenciaron un cambio en las relaciones de poder entre los gobiernos municipales y el capitán general e, igualmente, entre este y otros agentes del poder presentes en el archipiélago, principalmente los corregidores, lo que suscitó una frecuente y negativa conflictividad para el buen entendimiento de las instituciones. De este contexto se beneficiaron las élites locales, que conservaron su autonomía jurisdiccional y una parte de sus privilegios. Las grandes transformaciones y una parcial renovación de las listas municipales tendrían lugar tras los pronunciamientos liberales en el reino en 1820 .

En Horta las principales familias supieron maniobrar para defender sus privilegios y el poder adquirido a lo largo de los siglos, a pesar de los ataques al sistema vincular y a la aparición en escena de nuevos protagonistas. Los cambios tendrían lugar más tarde, ya en la segunda mitad del Ochocientos, pero esta es otra historia. 


\section{Bibliografía}

«À propos des catégories sociales de l'Ancien Régime» (2005), en Dire et vivre l'ordre social en France sous l'Ancien Régime, textes réunis par Fanny Cosandey, Paris, Éditions de l'École des Hautes Études en Sciences Sociales, pp. 9-43.

Arquivo dos Açores (1981), edição fac-similada da edição original, Ponta Delgada, Universidade dos Açores, vol. IV.

CAMARINHAS, Nuno (2018), «Lugares ultramarinos. A construção do aparelho judicial no ultramar português da época moderna», Análise Social, 226, LIII (1. ${ }^{\circ}$ ), pp. 136-160.

Cardoso, José Luís, Monteiro, Nuno Gonçalo, Serrão, José Vicente (org.) (2010), Portugal, Brasil e a Europa Napoleónica, Lisboa, Imprensa de Ciências Sociais, Instituto de Ciências Sociais da Universidade de Lisboa.

CERUtTI, Simona (1995), «La construction des catégories sociales», en Boutier, Jean e Julia, Dominique (eds.), Passés recomposés. Champs et chantiers de l'histoire, Paris, Éditions Autrement, pp. 224-234.

O Códice 529-Açores do Arquivo Histórico Ultramarino. A Capitania-Geral dos Açores durante o consulado pombalino (1988), introdução e fixação do texto por José Guilherme Reis Leite, Angra do Heroísmo-Ponta Delgada, Secretaria Regional de Educação e Cultura/Direcção Regional dos Assuntos Culturais-Universidade dos Açores/Centro de Estudos Gaspar Frutuoso.

Coelho, Maria Helena da Cruz, Magalhães, Joaquim Romero (1986), O Poder Concelhio: Das origens às Cortes Constituintes. Notas da História Social, Coimbra, Centro de Estudos e Formação Autárquica.

Costa, Ricardo Manuel Madruga da (2005), Os Açores em finais do regime de Capitania-Geral (1800-1820), Horta, Núcleo Cultural da Horta, vol. I.

Duncan, T. Bentley (1972), Atlantic Islands. Madeira, the Azores and the Cape Verdes in Seventeenth-Century Commerce and Navigation, Chicago-London, The Chicago University Press.

FaIrburn, Miles (1999), Social History: Problems, Strategies and Methods, Basingstoke and London, Macmillan.

ForJaz, Jorge, Mendes, António Ornelas (2009), Genealogias das Quatro Ilhas. Faial. Pico. Flores. Corvo, Lisboa, DisLivro Histórica, 4 vols.

Hernández Franco, Juan, Rodríguez Pérez, Raimundo A. (2013), «La sangre como elemento de cohesión y diferenciación social en la España del Antiguo Régimen», en Jiménez Estrella, Antonio; Lozano Navarro, Julián José; Sánchez-Montes González, Francisco e Birriel Salcedo, Margarita Ma (eds.), 
Construyendo Historia. Estudios en torno a Juan Luis Castellano, Granada, Editorial Universidad de Granada, pp. 349-357.

Hespanha, António Manuel (1986), As vésperas do Leviathan. Instituições e Poder Político. Portugal - Século XVII, Lisboa, edição do autor, vol. I.

Hespanha, António Manuel (1989), Visperas del Leviatán. Instituciones y poder político (Portugal, siglo XVII), Madrid, Taurus.

MaCEDo, António Lourenço da Silveira (1871), Historia das Quatro Ilhas que formam o Districto da Horta [...], Horta, Typ. de Graça Jr., vol. I.

MadeIra, Artur Boavida (1999), População e emigração nos Açores (1766-1820), Cascais, Patrimonia.

MagalHães, Joaquim Romero (1988), O Algarve Económico (1600-1773), Lisboa, Editorial Estampa.

Meneses, Avelino de Freitas de (1987), Os Açores e o Domínio Filipino (15801590), vol. I: A Resistência Terceirense e as Implicações da Conquista Espanhola, vol. II: Apêndice Documental, Angra do Heroísmo, Instituto Histórico da Ilha Terceira.

Meneses, Avelino de Freitas de (1993), Os Açores nas encruzilhadas de Setecentos (1740-1770), Ponta Delgada, Universidade dos Açores, vol. I: Poderes e Instituições.

Meneses, Avelino de Freitas de (1995a), Os Açores nas encruzilhadas de Setecentos (1740-1770), Ponta Delgada, Universidade dos Açores, vol. II: Economia.

Meneses, Avelino de Freitas de (1995b), «A Preponderância Geoeconómica do Faial na Conjuntura Açoriana de Setecentos», en Estudos de História dos Açores, vol. II: As ilhas na problemática do século XVIII, Ponta Delgada, Jornal de Cultura, pp. 43-64.

Monteiro, Nuno Gonçalo (1996), «O espaço político e social local», en Oliveira, César (dir.), História dos Municípios e do Poder Local [dos finais da Idade Média à União Europeia], Lisboa, Círculo de Leitores, pp. 162-165.

Monteiro, Nuno Gonçalo (1997), «Elites locais e mobilidade social em Portugal nos finais do Antigo Regime», Análise Social, XXXII (141), pp. 335-368.

Pimenta, Alfredo (1932), Vínculos Portugueses. Catálogo dos Registros Vinculares feitos em obediência às prescrições da Lei de 30 de Julho de 1860, e existentes no Arquivo Nacional da Tôrre do Tombo, Coimbra, Imprensa da Universidade.

Pinto, Maria Luís Rocha, Rodrigues, José Damião, MAdeIRA, Artur Boavida (2001), «A Base Demográfica», en Freitas de Meneses, Avelino de (coord.), Portugal. Da Paz da Restauração ao Ouro do Brasil, vol. VII da Nova História de Portugal, direcção de Joel Serrão e A. H. de Oliveira Marques, Lisboa, Editorial Presença, pp. 385-403. 
RoDrigues, João Bernardo de Oliveira (1978), «Do Livro VI das «Saudades da Terra», en Gaspar Frutuoso, Livro Sexto das Saudades da Terra, $2^{\mathrm{a}}$ ed., Ponta Delgada, Instituto Cultural de Ponta Delgada, pp. XXXXII.

Rodrigues, José Damião (1994), Poder Municipal e Oligarquias Urbanas: Ponta Delgada no Século XVII, Ponta Delgada, Instituto Cultural de Ponta Delgada.

Rodrigues, José Damião (2003 [2004]), São Miguel no século XVIII: casa, elites e poder, Ponta Delgada, Instituto Cultural de Ponta Delgada, 2 vols..

Rodrigues, José Damião (2005), «A Sociedade», en Matos, Arthur Teodoro de (coord.), Nova História da Expansão Portuguesa, vol. III: A Colonização Atlântica, Lisboa, Editorial Estampa, tomo I, pp. 446-491.

RoDrigues, José Damião (2006), «Para o socego e tranquilidade publica das Ilhas»: fundamentos, ambição e limites das reformas pombalinas nos Açores», Tempo, vol. 11, n. ${ }^{\circ}$ 21: Dossiê Ensino de História, pp. 157-183. <https://doi.org/10.1590/ S1413-77042006000200010>.

Rodrigues, José Damião (2008), «Senhores, rendeiros e jornaleiros. A atracção pelo Novo Mundo», en Matos, Artur Teodoro de; Freitas de Meneses, Avelino e Reis Leite, José Guilherme (dirs.), História dos Açores. Do descobrimento ao século XX, Angra do Heroísmo, Instituto Açoriano de Cultura, vol. I, pp. 353-382.

Rodrigues, José Damião (2009), «Categorias e hierarquias sociais no Antigo Regime. Um exemplo insular: São Miguel (Açores) no século XVIII», en Rivero Rodríguez, Manuel (coord.), Nobleza hispana, Nobleza cristiana. La Orden de San Juan, Madrid, Ediciones Polifemo, vol. 2, pp. 863-889.

Rodrigues, José Damião (2012a), «Entre Ficção e Realidade: O Faial e as Ilhas do Grupo Central no Relato da Segunda Viagem de James Cook», en Histórias Atlânticas: os Açores na primeira modernidade, Ponta Delgada, CHAM, pp. 61-78.

Rodrigues, José Damião (2012b), «Com exorbitância inaudita»: Elites Locais e Magistrados Régios na Horta em finais de Setecentos», en Garrido, Álvaro; Freire Costa, Leonor e Duarte, Luís Miguel (orgs.), Estudos em Homenagem a Joaquim Romero Magalhães. Economia, Instituições e Império, Coimbra, Almedina, pp. 215-225.

Rodrigues, José Damião (2015a), «Nobreza e governança no Faial no Antigo Regime», en $O$ Faial e a Periferia Açoriana nos Séculos XV a XX. A Horta e os Açores na História da Aviação: nos 75 anos do $1^{\circ}$ voo regular transatlântico da Pan American Airways. Actas do VI Colóquio, Horta, Núcleo Cultural da Horta, pp. 181-195.

Rodrigues, José Damião (2015b) «Frutuoso, Gaspar. Historiador», en Enciclopédia Açoriana, Centro de Conhecimento dos Açores, Direção Regional da Cultura. $<$ http://www.culturacores.azores.gov.pt/ea/pesquisa/Default.aspx?id=9828>. 
Rodrigues, José Damião (2016), «O comércio dos portos açorianos com o Brasil e a legislação régia (séculos XVII-XVIII): os «navios do privilégio», en Polónia, Amélia e Rivera Medina, Ana María (eds.), La gobernanza de los puertos atlánticos, siglos XIV-XX. Políticas y Estructuras Portuarias, Madrid, Casa de Velázquez, pp. 261-272.

Rodrigues, José Damião y Costa, Ricardo Manuel Madruga da (2010), «Entre o Reino e o império: os Açores e a viragem de 1807-1808», en Cardoso, José Luís; Monteiro, Nuno Gonçalo e Serrão, José Vicente (org.), Portugal, Brasil e a Europa Napoleónica, Lisboa, Imprensa de Ciências Sociais, Instituto de Ciências Sociais da Universidade de Lisboa, pp. 211-227.

Serpa, António Ferreira de (1915), «Juíses!... », O Instituto. Revista Scientífica e Literária, Coimbra, vol. 62, pp. 32-42, 145-152 e 187-194.

Silva, Francisco Ribeiro da (1988), O Porto e o seu termo (1580-1640). Os homens, as instituições e o poder, Porto, Arquivo Histórico/Câmara Municipal do Porto, 2 vols.

SoARes, Sérgio Cunha (1995), O Município de Coimbra da Restauração ao Pombalismo. Poder e Poderosos na Idade Moderna, dissertação de doutoramento em História Moderna, Coimbra, Faculdade de Letras da Universidade de Coimbra, 2 vols., policopiado.

SousA, Paulo Silveira e (2008), «As elites insulares», en Matos, Artur Teodoro de; Freitas de Meneses, Avelino de e Reis Leite, José Guilherme (dirs.), História dos Açores. Do descobrimento ao século XX, Angra do Heró́smo, Instituto Açoriano de Cultura, vol. I, pp. 579-611.

VAlladares, Rafael (2010), A conquista de Lisboa. Violência militar e comunidade política em Portugal, 1578-1583, Lisboa, Texto Editores. 
